\title{
A Modeling Technique For Enterprise Agility
}

\author{
Joshua C. Nwokeji \\ Comp.\& info. Sc. Dept. \\ Gannon University, USA \\ Nwokeji001@gannon.edu
}

\author{
Balbir Barn \\ Comp.Sc. Dept. \\ Middlesex Uni. UK \\ b.barn@mdx.ac.uk
}

\author{
Tony Clark \\ Comp.Sc.Dept. \\ Sheffield Hallam Uni.UK \\ Vinay Kulkarni \\ Tata Cons.Services \\ Pune, India \\ t.clark@shu.ac.uk vinay.vkulkarni@tcs.com
}

\begin{abstract}
Enterprise agility, i.e., the ability of enterprises to respond to changes, is a core imperative for effective change management. It can improve operational efficiency as well as support resource optimization. Yet, it is challenging and a major concern for corporate executives. To facilitate agility, it can be useful to design modeling constructs for representing changes. Such modeling constructs can help stakeholders to represent and better understand change concepts. This research contributes by extending existing enterprise modeling approaches with new modeling constructs for representing concepts of change. These modeling constructs are integrated into a conceptual model. To demonstrate utility, we apply this meta-model to represent a real-world case study and discuss some lessons learned in this process. One major challenge faced by
\end{abstract}

\section{Problem and Motivation}

One major challenge faced by modern day enterprises is the ability to manage changes and market dynamics [1]. Enterprises depend on, interact with, and transact in an increasingly dynamic business environment. Therefore, they can be vulnerable to spontaneous changes and uncertainties, which can threaten the survival and competitive abilities of enterprises. The changes and uncertainties experienced by enterprises are often caused by change drivers, broadly defined as circumstances and events that can lead to changes in an enterprise [2]. Examples of popular change drivers include regulatory compliance, technology updates and obsolescence, competition, and changes in business requirements. In order to become competitive and viable in a turbulent business environment, enterprises require agility [1].
Enterprise agility, defined as the ability of enterprises to detect and adapt to changes timely and effectively, is a core imperative to organizational survival in a changing business environment [3]. It can improve operational efficiency, enhance competitive ability, and make enterprises resilient to changes [4]. Yet, enterprise agility is challenging, difficult to achieve, and a major concern for corporate executives [3, 4, 5]. Van Oosterhout et al [5] believe that despite existing scholarly efforts towards actualizing agility, till date, no one knows how to achieve agility. Similarly, [3] observe that enterprises are still looking for ways to achieve agility.

The above definition suggests that the ability to detect and respond to changes are central to achieving enterprise agility. This implies that for an enterprise to facilitate or achieve agility, its stakeholders should have techniques or strategies that can help them to detect and respond to changes. We opine that the representation (modeling) of enterprise change, as well change features and related concepts ${ }^{1}$, can enable stakeholders acquire clarity, knowledge, and understanding that could help them to design, develop, and implement the techniques or strategies required to detect and respond to changes effectively. In order to achieve such clarity, knowledge, and understanding, certain questions are pertinent, and thus should be answered by stakeholders in a structured and consistent way. For instance, what exactly is an enterprise change? What are the causes and origin of enterprise changes? What actions and strategies are suitable for responding to a given change? Are there alternative actions for responding to a particular change? What environmental factors lead to changes? How exactly do changes affect an enterprise? More so, providing answers to these questions can enable

\footnotetext{
${ }^{1}$ In this context, change features and related concepts refer to those concepts e.g., change driver, and change impact, discussed in Section 5 that can be used to elaborate, specify, and convey meaning to enterprise changes.
} 
stakeholders to clarify any ambiguous or tacit concepts associated with enterprise changes, motivate and encourage implementation of concerted initiatives to detect and respond to changes.

We believe that conceptual modeling can support enterprise stakeholders to represent change and related concepts, as well as answer the above questions. Research carried out by prominent scholars such as Mylopoulos [6] shows that conceptual modeling can be useful in describing and understanding concepts in a given area of interest. Also, conceptual model provides commonly agreed notations that can be used to represent and define the meaning of physical world concepts in an understandable [6]. Likewise, a conceptual model for enterprise change can help stakeholders capture and structure knowledge of enterprise changes. Hence, this research proposes a conceptual model that would support stakeholders to explicitly represent, define, understand, articulate as well as communicate concepts and knowledge about enterprise changes.

The proposed conceptual model can potentially benefit enterprise stakeholders in supporting agility. For instance, it provides modeling constructs/concepts such as change driver, which can be used to describe and represent the causes of change. This can help stakeholders to reason about, as well as understand the root causes and rationale behind a given enterprise change. When the root cause of any problem is clearly identified and understood, it is always easier to proffer viable solutions to that problem. Hence, understanding the root cause of an enterprise change can enable stakeholders to proffer viable strategies for adapting to that change. Furthermore, understanding the rationale behind a given change can motivate adequate planning and prudent allocation of resources for adapting to the change, thereby achieving and facilitating enterprise agility.

To enhance readability and provide further explanation towards this contribution, we organize the rest of this paper as follows: Section 2 provides a brief review of existing enterprise agility approaches and discusses their limitations with regards to modeling supports. The methodology used in conducting this research is described in Section 3. Section 5 describes the modeling constructs and presents the abstract syntax model of the proposed conceptual model. Afterwards, an industry case study is used in Section 6 to describe how the proposed concepts and the resulting conceptual model can be used to represent enterprise changes. This is followed by Section 7 where discussions and lesson learned are presented. Section 8 discusses the limitation of this research, while the conclusion and future work are presented in 9 .

\section{Review of Related Approaches}

There exist a considerable number of approaches in literature, that intends to support enterprise agility and/or change management. Popular among existing approaches include the dynamic capability framework proposed by Teece et al [26], and Rouse's theory of enterprise transformation [27]. These two approaches relate very well with enterprise agility, and have made appreciable contributions to enterprise agility research and practice, but do not consider how conceptual modeling can be applied to support representation of enterprise changes to enhance stakeholders' understanding and knowledge. For instance, dynamic capability framework provides strategies to integrate, build, and reconfigure capabilities or competences to enable enterprises gain competitive advantage and create wealth amidst changing environment [26]. Similarly, other enterprise agility research focus on areas such as the role of information technology in enterprise agility [23], and evaluation and measurement of enterprise agility [24] If conceptual modeling is considered at all, it is either vaguely described and/or lack important concepts, for instance see [28, 29, 30].

On the other hand, enterprise architecture frameworks (EAF) or approaches generally provide techniques for describing the high level contents, structure, business processes, and Information Technology (IT) of enterprises [9], whilst providing little or no concepts to help stakeholders model the changes faced by enterprises. Among varieties of competing EAFs, TOGAF (The Open Group Architecture Framework) [2] , ZAF (Zachman Architecture Framework) [7], and ARCHIMATE ${ }^{2}$ [31] are popular and widely used, hence we use them as the basis of our study. EAFs can benefit enterprises in other areas such as strategic alignment, but, as shown in Table 1, most of them did not explicitly define modeling constructs for capturing, and representing enterprise changes. For this reason, they can be regarded to have limited capabilities with regards to modeling enterprise changes and related concepts.

This also applies to other popular approaches such as $i^{*}$ [10], BMM [12], and UML [11] used in enterprise modeling. The $i^{*}$ [10], and BMM [12] modeling approaches can be taken to represent enterprise goal oriented models (GOM), which are primarily used to model the rationale, motivations, and intentions behind the existence of an enterprise [32, 10]. The unified modeling language $\mathrm{UML}^{3}$ is a family of languages generally used to model and analyze information

\footnotetext{
${ }^{2}$ http://tinyurl.com/h8yubcc

${ }^{3}$ http://www.uml.org/
} 
Table 1. Comparison of Agility Modeling Constructs with Enterprise Modeling Constructs

\begin{tabular}{|c|c|c|c|c|c|c|c|}
\hline $\begin{array}{l}\text { Modeling } \\
\text { Constructs for Agility }\end{array}$ & TOGAF [2] & ZAF [7] & ARCHIMATE [8] & ARMOR [9] & $i^{*}[10]$ & UML [11] & BMM [12] \\
\hline Change Driver [13][14][15][16] & $\mathrm{x}$ & $\mathrm{x}$ & $\mathrm{x}$ & $\mathrm{x}$ & $\mathrm{x}$ & $\mathrm{x}$ & $\mathrm{x}$ \\
\hline Change $[4][5][16]$ & $\mathrm{x}$ & $\mathrm{x}$ & $\mathrm{x}$ & $\mathrm{x}$ & $\mathrm{x}$ & $\mathrm{x}$ & $\mathrm{x}$ \\
\hline Goal* $^{*}$ & $*$ & $*$ & $\mathrm{x}$ & $\sqrt{ }$ & $\sqrt{ }$ & $*$ & $\sqrt{ }$ \\
\hline Change Impact* & $\mathrm{x}$ & $\mathrm{x}$ & $\mathrm{x}$ & $\mathrm{x}$ & $\mathrm{x}$ & $\mathrm{x}$ & $\mathrm{x}$ \\
\hline Actions [17][18] & $\mathrm{x}$ & $\mathrm{x}$ & $\mathrm{x}$ & $\mathrm{x}$ & $\mathrm{x}$ & $\mathrm{x}$ & $\mathrm{x}$ \\
\hline Agility Enabler [19][20][21][4] & $\mathrm{x}$ & $\mathrm{x}$ & $\mathrm{x}$ & $\mathrm{x}$ & $\mathrm{x}$ & $\mathrm{x}$ & $\mathrm{x}$ \\
\hline Change Indicator [22][1][23] & $\mathrm{x}$ & $\mathrm{x}$ & $\mathrm{x}$ & $\mathrm{x}$ & $\mathrm{x}$ & $\mathrm{x}$ & $\mathrm{x}$ \\
\hline Data [24][25] & $\sqrt{ }$ & $\sqrt{ }$ & $\sqrt{ }$ & $\sqrt{ }$ & $\mathrm{x}$ & $\sqrt{ }$ & $*$ \\
\hline Business Process* & $\sqrt{ }$ & $\sqrt{ }$ & $\sqrt{ }$ & $\sqrt{ }$ & $\mathrm{x}$ & $*$ & $\sqrt{ }$ \\
\hline Stakeholder* & $\sqrt{ }$ & $\sqrt{ }$ & $\sqrt{ }$ & $\sqrt{ }$ & $\sqrt{ }$ & $*$ & $*$ \\
\hline
\end{tabular}

systems and software of an enterprises [11].

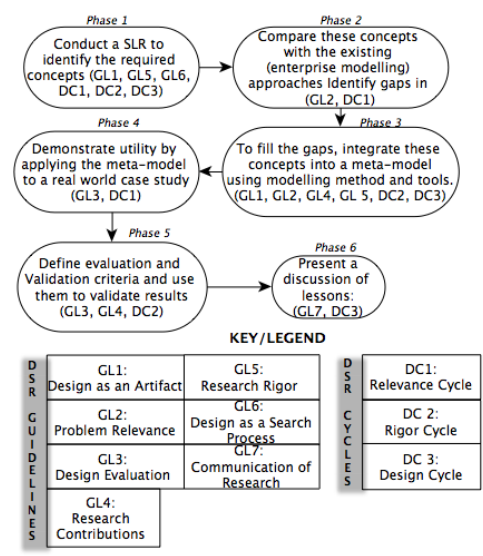

Figure 1. Our Research Approach

\section{Research Methodology}

This research aims at designing new modeling constructs or artifacts to contribute in solving enterprise agility problems. The creation of new (modeling) artifacts is the primary concern of design science research (DSR) [33]. Therefore, to ensure good quality design and satisfy the requirements for effective design, we adopt and adapt the DSR methodology (DSR cycles and DSR guidelines) proposed by Hevner et al [33][34], and used in relatively similar design projects [35][36]. As shown in Figure 1, we breakdown our research process into 6 Phases, and map each phase to correspond to the DSR guidelines (GL) and design cycles (DC). The first step i.e., Phase 1, involves the specification of the required concepts through a SLR. The details of the SLR has been discussed in Section 3.1, and summarized in Table 2 .

The DSR GL2, GL3, and DC1 encourage the identification of research gaps and designing appropriate artifacts, in this case a meta-model, to fill those gaps. These correspond to our Phases 2 and 3. To identify gaps, we use the concepts identified in SLR to compare existing enterprise modeling approaches; a summary of this is presented in Table 1. A meta-model is proposed, in Section 5 with an abstract presented in Figure 2, to fill these gaps. According to DSR GL1, GL2, GL4, GL5, DC2, and DC3, utility of design artifacts can be demonstrated by applying them to a real world case study, this corresponds to our Phase 4. The real world case study is described in Section 6.1. Section 6.2 together with Figures 3 and 4 explain how this case study is applied to the proposed conceptual model. DSR GL3, GL4, and DC2 also suggest that the results of applying design artifacts to real world case study must be validated and evaluated using a well defined criteria. This corresponds to our Phase 5, as described in Section 6. Finally, as suggested by DSR GL7 and DC3, we present a discussion of lessons learned in Section 7 , i.e., Phase 6.

\subsection{Concepts and Features of Change}

In order to identify and specify the basic concepts required to develop the meta-model, we carried out a systematic literature review (SLR) following the guideline proposed in [37], which specifies the review processes and protocols to be followed while conducting a SLR. These include defining the research questions, identifying relevant search databases, search keywords, and search strings, as well as establishing the selection and quality criteria. Summary of these are presented in Table 2. The research question addressed in this SLR is as follows: What are the basic concepts required to develop a conceptual meta-model to support enterprise agility and change management?

After conducting the search, a total of 186 papers were retrieved and downloaded into Bibtex - a reference management system. To identify papers to be included in primary studies, we applied the selection and quality criteria listed on the right hand side of Table 2. At the end 16 papers were selected for primary studies. Finally we reviewed each of these papers included in the primary studies to identify the concepts relevant to 
Table 2. Systematic Literature Review Processes and Protocols

\begin{tabular}{|c|c|c|c|}
\hline Search Databases & Search Keywords & Search Strings & Selection and Quality Criteria \\
\hline $\begin{array}{l}\text { - ACM Digital Library } \\
\text { - IEEE Xplore } \\
\text { - EBSCO Host } \\
\text { - Springer Link } \\
\text { - Google Scholar } \\
\text { - Science Direct }\end{array}$ & $\begin{array}{l}\text { [A1]Enterprise Agility } \\
\text { [A2]Enterprise Change } \\
\text { [A3]Organizational Agility } \\
\text { [A4]Agile Enterprise } \\
\text { [B1] Concepts } \\
\text { [B2]Terminologies } \\
\text { [B3]Features }\end{array}$ & $\begin{array}{l}\text { (A1 OR A2 OR A3 OR A4) AND B1 } \\
\text { (A1 OR A2 OR A3 OR A4) AND B2 } \\
\text { (A1 OR A2 OR A3 OR A4) AND B3 }\end{array}$ & $\begin{array}{l}\text { Published between } 1994 \text { and } 2014 \\
\text { Relevant to Enterprise agility } \\
\text { Exclude position papers } \\
\text { Exclude keynotes and symposium } \\
\text { Relevant to change management } \\
\text { Title and keyword must be relevant } \\
\text { Only Journal, conference, and workshop } \\
\text { articles }\end{array}$ \\
\hline
\end{tabular}

enterprise agility and change management. The selected concepts and their references are presented at the extreme left of Table 1, and discussed in Section 5. This research argues that any modeling approach suitable for enterprise agility should include these concepts. Thus, they (the concepts) are used as the basis of comparison with the existing approaches. Note that some concepts are marked with asterisk $(*)$ in Table 1 , this implies that they are derived from other concepts by the Authors. For instance, the goal concept is not included in literature as a concept of change. But it is important because a goal can be used to express change in an understandable form.

\section{A Brief Theory of Conceptual Modeling}

A conceptual model can be defined as an abstraction or representation of relevant concepts in an aspect of the physical world. Such abstraction normally enhances the communication and understanding of knowledge (information and data), problems, and the solutions to those problems [38]. Depending on its purpose and the target audience, a conceptual model can be static or dynamic [39]. Dynamic models are usually behavioral and can be executable or easily supported with automation. On the other hand, static models such as entity relationship model (ERM) are not necessarily executable, and are primarily used to represent concepts of real world to enhance understanding and communication [39]. It is important to note that change model proposed in this paper is a static model, whose aim is to help stakeholders represent and examine change concepts for easy understanding.

The essential features of a conceptual model, such as abstract syntax and concrete syntax are captured and described in a meta-model [38]. Abstract syntax is the structural description of the concepts of a conceptual model, the relationships between these concepts, and how the concepts can be combined into a model. In an abstract syntax, the concepts of the modeling language are usually referred to as abstract elements. Abstract elements are also called model constructs or model elements. The concrete syntax provides a set of graphical notations, symbols, or shapes for presenting
Table 3. Description of Change Modeling Constructs

\begin{tabular}{|c|c|}
\hline Concepts & Description \\
\hline $\begin{array}{l}\text { Change } \\
\text { Driver }\end{array}$ & $\begin{array}{l}\text { The change driver }[13][16] \text { generally refers to event or circumstance that can } \\
\text { bring about changes in an enterprise. Examples of popular change drivers } \\
\text { include, regulatory compliance, technology obsolescence, and competition. } \\
\text { Change drivers describes the root cause of a change, they are important } \\
\text { and thus should be documented and communicated to stakeholders. The } \\
\text { communication association, a thick dotted line that links a change driver } \\
\text { (and/or a change) to stakeholders, can be used to this end. }\end{array}$ \\
\hline Change & $\begin{array}{l}\text { A change }[4][5][16] \text { represent any transition from the current (AS-IS) } \\
\text { state of an enterprise to a target (TO-BE) state; leading to modifications of } \\
\text { enterprise goals, business process, and/or data(information). }\end{array}$ \\
\hline Goals & $\begin{array}{l}\text { In enterprise modeling, goals are model constructs that describe the rationale } \\
\text { behind an action, and can also be used to capture the intentions and } \\
\text { objectives of a system or stakeholder [10]. A goal can be of any of the } \\
\text { following types: parent, sub-goal, disjunction, conjunction, and atomic } \\
\text { goal [10, 40, 32]. Parent goals are goals that can be decomposed into one } \\
\text { or more sub-goals. A sub-goal provides some alternatives for achieving } \\
\text { a parent goal. Two or more sub-goals can be obligatory alternatives for } \\
\text { achieving a parent goal, in this case they are called conjunction goals (con). } \\
\text { Equally, sub-goals can be optional alternatives for achieving a parent goal, } \\
\text { in which case they are called disjunction goals (dis). An atomic goal has } \\
\text { no alternative and cannot be further decomposed into sub-goals [41, 32, 42]. } \\
\text { Atomic goals can be used to define a constraint over a given property, such } \\
\text { as cost, product, and staff, of an enterprise. This constraint is known as } \\
\text { a condition. For instance, the atomic goal, "employ first class graduates } \\
\text { only", places a condition on all employees of the enterprise. Conditions are } \\
\text { defined by expression, e.g., grade = "first class" }\end{array}$ \\
\hline $\begin{array}{l}\text { Change } \\
\text { Impact }\end{array}$ & $\begin{array}{l}\text { Normally, a change will have effects or consequences to the host enterprise, } \\
\text { these can be captured or modeled using the change impact construct [43], } \\
\text { simply referred to as impact }\end{array}$ \\
\hline
\end{tabular}

an abstract syntax of a conceptual model to the end user [38]. In the section that follows, we discuss the meta-model of the proposed change model.

Table 4. Continuation of Table 3

\begin{tabular}{|l|l}
\hline Concepts & Description \\
\hline Action & $\begin{array}{l}\text { The action [17] model construct represents the functions or operations an } \\
\text { enterprise should perform in order in order to respond or adapt to changes } \\
\text { effectively. It is possible to have It can be useful to represent all possible } \\
\text { actions for adapting to a given change, using the alternative model construct. } \\
\text { So that stakeholders will have a richer pool of actions to choose from, while } \\
\text { leaving the non-selected actions for contingency purposes. Additionally, by } \\
\text { specifying alternative actions, the relative advantages and disadvantages of } \\
\text { each action can be analyzed. In this way the most suitable and viable action } \\
\text { and strategies can identified and selected in a systematic way. }\end{array}$ \\
\hline $\begin{array}{l}\text { Agility } \\
\text { Enabler (or } \\
\text { Enabler) }\end{array}$ & $\begin{array}{l}\text { The Agility enabler [19,4] represent activities that can support the actions for } \\
\text { adapting to changes. Physical enablers are tasks performed by stakeholders. } \\
\text { Logical enablers model automated events and usually expressed as a } \\
\text { business process. A business process is loosely defined as a set of coherent } \\
\text { activities for actualization a business outcome [44]. In our model, an activity } \\
\text { can be conditional or sequential. A conditional activity usually gives a } \\
\text { boolean result (true or false) which directly links to two other activities. } \\
\text { While a sequential activity do not give a boolean result and directly links } \\
\text { to one activity. }\end{array}$ \\
\hline $\begin{array}{l}\text { Change indicators [22, 1] are environmental events that are most likely to } \\
\text { Indicator } \\
\text { trigger change drivers. For instance, events such as recession may engineer } \\
\text { a government regulation that can lead to changes in an enterprise. Each } \\
\text { change indicator has a threat level, which defines its likelihood to trigger a } \\
\text { change driver. A threat level can be severe, mild, or low. }\end{array}$ \\
\hline
\end{tabular}

\section{The Change Meta-Model}

In this section, we describe the abstract syntax and concrete syntax of the proposed change conceptual 
model. The concepts that make up the abstract syntax of the change model are those identified from the systematic literature review in Section 3.1.These concepts are presented and described in Tables 3 and 4. As shown in these tables, each concept is followed by a description. Some concepts, such as data and business process, are popularly known and available in most of the existing approaches, their explanations are omitted here. We focus more on the new model constructs that are either implicit or lacking in existing approaches.

Using model driven development methods and eclipse modeling framework (EMF), we integrate these model constructs into an abstract syntax, see Figure 2. Detailed discussion of model driven development (MDD) methods are beyond the scope of this paper. However, further details of MDD and EMF can be found in [38] and in [45] respectively. In the abstract syntax shown in Figure 2, relationships between modeling elements are shown with directed arrows, while abstract classes are shown in grey colors. The concrete syntax, i.e., the symbols for representing the concepts are shown in Figure 3.

\section{Utility of the Proposed Conceptual Model}

As proposed by Henver et al [34][33], DSR and design science cycle require the demonstration of utility or usefulness of design artifacts using accurate methods. Various methods have been suggested for demonstrating the utility of conceptual models. For this research, we will focus on the quality methods, where utility is demonstrated using some quality criteria [46]. We will use two key quality criteria to demonstrate the utility of our model. These include completeness and consistency.

Completeness criterion requires that a meta-model has sufficient model constructs to represent reality in a given domain [46]. The reality in our case will be the change features in the real world case study described in Section 6.1. On the other hand, the consistency ${ }^{4}$ criterion requires that each model construct is explicitly defined, i.e., there must not be ambiguity or conflict in meaning [46]. In Section 6.2, we use our meta-model to represent a real world case study, i.e., reality. Since our meta-model can be used to represent reality in the domain of change, we can claim that it is complete. Also, while representing this reality, we did not experience any ambiguity or conflict in the meaning of the model constructs. We can also say that our meta-model is consistent.

\footnotetext{
${ }^{4}$ http://osm7.cs.byu.edu/ER97/workshop4/tvdb.html
}

\subsection{Case Study}

Consider an organization that provides IT services such as development of software systems. The organization bids for projects through requests for proposals (RFP), and put suitably skilled employees and other resources to work on the bid won. The organization stays viable by hiring suitably skilled employees using a well defined recruitment process. To respond to skills shortage in its home country, the organization recruit most of its employees from abroad. However, due to surge in immigration and high level of unemployment, a resident employment legislation (REL) has been enforced by the government. This limits the immigration of foreign workers, and secure jobs for citizens and residents. In effect, enterprises are required to tighten eligibility criteria for hiring foreign workers so that more more citizens can be employed. Furthermore, due to the influence of competitions and a new IT service company, the organization lost about $24 \%$ of its customers. This results to financial loss. In order to survive, the organization has to respond to these changes.

\subsection{Application to case study}

The case study above shows that there are two cases of change drivers that this organization has to deal with. Case 1: is Regulatory Compliance and Case 2: is Competition. We apply the proposed meta-model to model these cases, using the steps discussed below, and afterwards presents a summary of the lessons learned. The resulting models are presented in Figures 3 and 4. The new model constructs and the notations used to represent them are shown in Figure 3. The steps below can be used as a guide while applying our language to model a change case. However, its important to note that these steps are not prescriptive:

Step 1: Analyze the change situation to identify and represent the change driver. This can be done by examining the change case/situation. For the case study under consideration, the change driver for case 1 is government regulation, which requires enterprises to reduce the immigration of foreign workers by raising employment/recruitment criteria for foreign applicants. In case 2, the competition change driver, due to new IT service providers caused the organization to lose some of its clients and competitive advantage. As shown in Figures 3 and 4, these change drivers should be represented explicitly in a clear and understandable form. Then the communication association can be used to communicate them to the concerned stakeholders in 


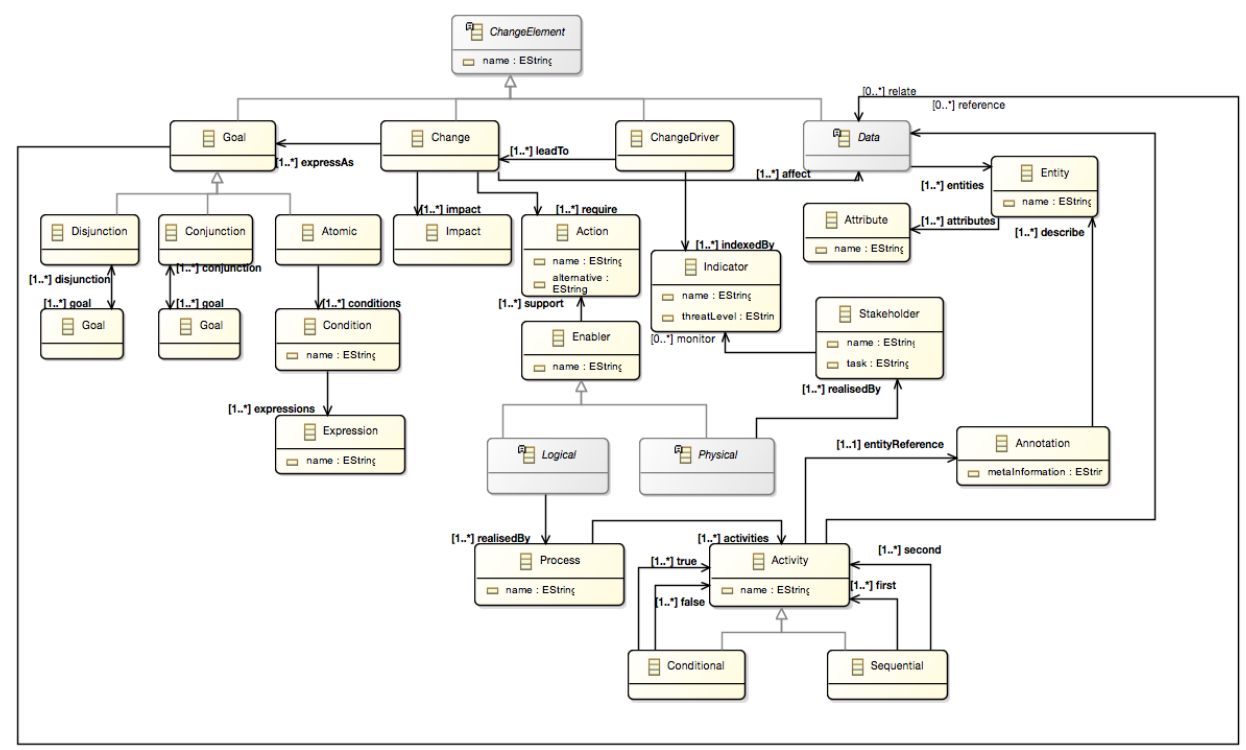

Figure 2. The Change Meta-Model

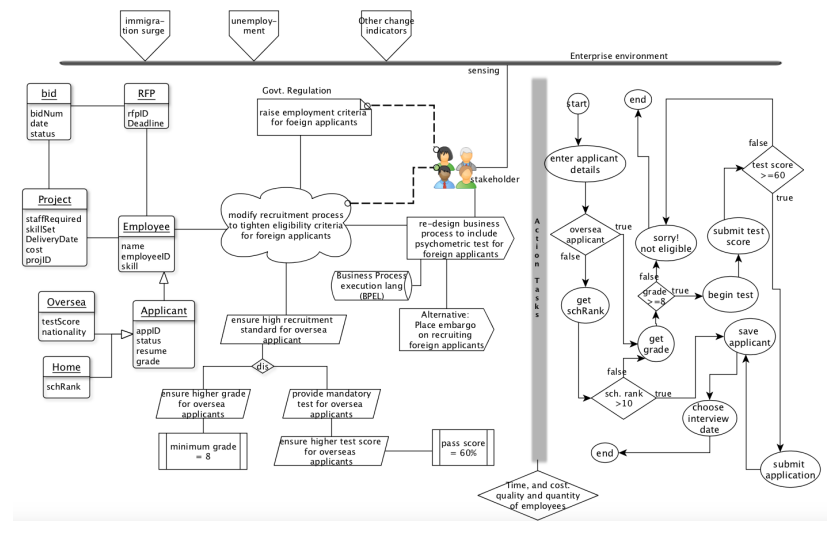

Figure 3: Regulatory Compliance Change Model.

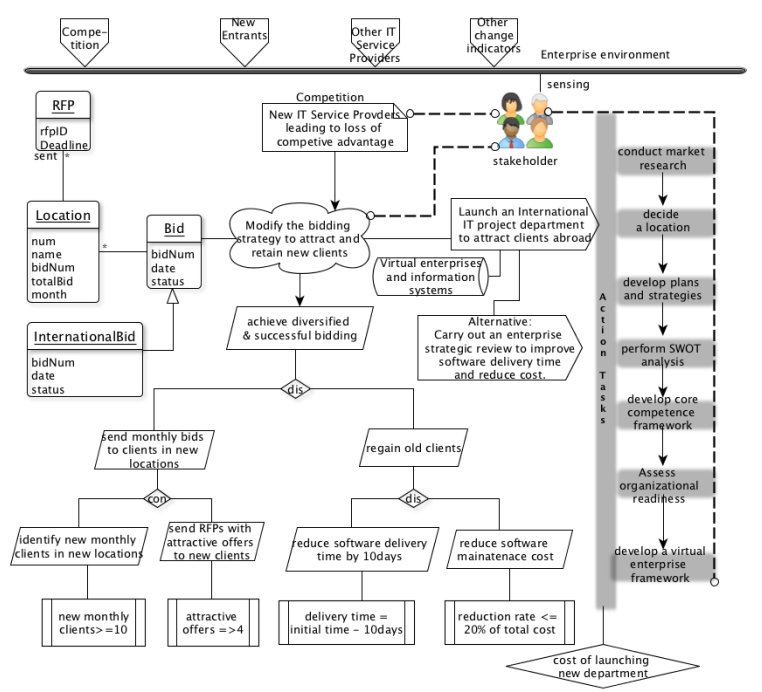

Figure 4: Competition Change Model. 


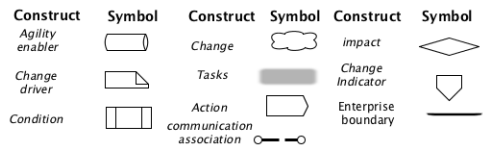

Figure 3. Legend

the enterprise.

Step 2: Specify and represent the change(s) that can occur as a result of change driver. To do these, users should examine the change driver alongside the current state of the enterprise, so that they can know the domain(s) (process, data, technology, etc) of the enterprise that relates to the change. In this way, they can understand the required modification(s) and represent this as a change. In case 1, the change driver requires a tighter recruitment criteria for foreign applicants. Also the case study suggests that the enterprise has an existing recruitment process. Possibly, a good way to tighten the recruitment criteria will be to modify the existing recruitment (business) process. Therefore, the change can be modeled as follows: modify recruitment process to tighten eligibility criteria for foreign applicants. How the recruitment process will be modified should be determined by stakeholders and modeled using the action construct. On the other hand, case 2 requires the organization to come up with new reliable strategies to regain its competitive advantage. This can be achieved in many ways. One of such ways, as shown in Figure 4, is to modify bidding strategies to attract and retain new customers. The change in both cases should be communicated to stakeholders using the communication association.

Step 3: Express the change using goal model. Changes should be described in a precise, clear, and concise manner to avoid ambiguity and vagueness. This can be done by expressing them (changes) as goals, and decomposing them into achievable objectives using the goal decomposition constructs discussed in Table 3. So that the desired changes can be understood and shared as a common objectives. Also concerted effort can be made to develop winning strategies for adapting to the change. As shown in the Figures, the root goals in both cases were first identified, then decomposed into achievable objectives, and made concrete by attaching a condition to them.

Step 4: Identify and represent the action(s) required for adapting to change. Formulating actions for adapting to changes can be a discretionary and heuristic decision making process, as well as challenging and difficult. To support this step, stakeholders/users can examine the change and change driver to derive ideas and clues. For case 1, the change driver requires enterprises to raise the eligibility criteria for foreign applicants, and the change requires modifications in the recruitment process to achieve this. Hence, we started thinking of various ways of modifying the recruitment process to raise eligibility criteria for foreign applicants.

A possible option will be to introduce an employment psychometric test for foreign applicants. An alternative action will be to place embargo on recruiting foreign applicants. Introducing psychometric test to the recruitment process will lead to re-designing the business process which has cost and time implications. On the other hand, placing embargo on hiring foreign applicants can have adverse effect on the quantity and quality of employees. This can also affect the quality of projects, since employees work on projects. The re-designed process is shown at the right hand side of Figure 3. The selected action in case 2 does not require business process re-designing. It requires that the organization launch an international IT project department to attract customers abroad. An alternative action to this has also been identified and modeled as shown in Figure 4. Any of these actions will require a set definite action tasks. These tasks can be decided by top management and communicated to other stakeholders concerned. The action tasks for case 2 is at the extreme right of Figure 4.

Step 5: Identify and model enablers that can support the action. A critical examination of the selected actions, from Step 4, can provide a clue to determine the enabler. In case 1 , the selected action is to introduce psychometric test in the recruitment process for foreign applicants. Both physical and logical enablers can be used to enable this action. Physical enablers such as stakeholders can design the psychometric test, as well as re-design the business process to include this test. While technologies such as business process execution language (BPEL) can be used as logical enablers. Similarly, information systems and technologies can be used to enable the action in case 2 .

Step 6: Identify and model the data/information that can be affected by change. To achieve this, the change and/or change driver can be examined to identify the referenced entities and attributes. In case 1, the change directly relates to the foreign applicant entity and attributes. A foreign applicant is a specialized type of employee. Hence, this change will directly affect the employee and applicant entities and their attributes. But the employee entity relates to other data. For instance, an employee work on project and bid, as well as examines RFP. Therefore, this change will propagate and affect other entities and attributes such as project and bid. To understand extent, type, and intensity of this impact, further analysis such as change impact analysis, 
can be carried out. However, these are beyond the scope of this paper. This same principle is also applied to identity the referenced data in case 2 as shown in Figure 4.

Step 7: Identify the impact of change to the enterprise. This can be done by a careful study of the enterprise's current state, together with the described change, action, and/or change driver. In case 1, the change driver demands a tighter employment criteria for foreign applicants, which can lead to change in the existing business process of the enterprise. This change will require an action to re-design the business process to accommodate psychometric test for foreign applicants. Re-designing business process can have time, cost, and other implications on the enterprise. We identify and model these as impact. In addition, since the demand of this change driver is to reduce foreign applicants, the change can also affect the quality and quantity of employees, and can impact other entities that relate to the employee entity. Further analysis can be required to identify the intensity of the impact. In case 2 , the impact will be the time, cost, and other ramifications involved in establishment a new department abroad.

Step 8: Identify and model change indicator. This can be done by looking at the environmental current affairs that led to this change driver. For case 1, the change driver (government regulation) is in response to surge in immigration and high level of unemployment. While the competition change driver in case 2 is primarily due to new entrant. The essence of modeling them is to notify stakeholders of the environment issues that led to this change. So that they can be in constant alert and monitor the environment for the occurrence of similar issues in the future. If similar or any of such environmental issue becomes predominant/popular in a the future, stakeholders can capture such an issue and set the threat level to severe. In this way, they can start anticipating the type of change driver and change it can cause, as well as the impact the change can have. The meta-model proposed in this paper can be used to stimulate a model of the enterprise to reflect these anticipations.

\section{Discussion and Lessons}

In our attempt to apply our meta-model in modeling the features of change identified from the case study, we learn some useful lessons. These are discussed as follows:

(a) By modeling a change driver, we found it easier to understand the root cause of the change. This also helped us to specify the modifications that should be made to the current state of the enterprise in response to the change driver. By so doing, we were able to select an action for adapting to the change.

(b) Expressing a change as a goal, made it easier to decompose the change into achievable objectives. By so doing, the steps required to adapt to the change is made more explicit, understandable, and are linked to conditions that can be automated using IT systems.

(c) Most of the steps involved in using our language overly rely on user analysis. There is little or no support for automation. In addition, there is no systematic approach or method for performing these analysis. These can make it difficult to be used by stakeholders with little or no knowledge of conceptual modeling. This is one of the current limitations of our approach and should be the focus of our future work.

(d) Representing alternative actions is a useful approach in our method. It helped us to represent and reason about other possible strategies for adapting to a given change. By so doing, we are provided with richer alternatives and are equipped to assess the implications of each alternative. Such assessment facilitates the selecting of a better action and also provides contingency actions in case the selected one did not achieve the desired objectives.

\section{Study Limitation}

In this Section, we discuss two main limitations of our conceptual model:

Validation and Evaluation Method: The proposed conceptual model is evaluated with a case study. Yet, it is often difficult to generalize the results from a case study evaluation, especially if the case study is from a single industry, as the case of this research [47]. Furthermore, the case study used to validate this research contributions is not based on statistical data. Instead, it is based on textual descriptions which can subject it to the interpretation, analysis, knowledge, and expertise of the researcher [47]. This can introduce some elements of bias and raise questions or doubts about the accuracy of the results obtained from experimenting with the research contributions.

Lack of Automation: Although automation and software tools may not be mandatory prerequisites for supporting enterprise agility. They can be useful and helpful to enterprise agility initiatives. However, in its current state, the approach proposed by this research does not include automation and software tools. Instead it is limited to manual approach, which may be cumbersome, and can involve some errors, 


\section{Conclusion and Future Work}

Enterprise agility is regarded as a core imperative for the survival of enterprises in a dynamic business environment. However, it is difficult to achieve and a major concern for enterprise executive. Existing methods such as enterprise architecture approaches, dynamic capabilities, and theory of enterprise transformation do not consider how conceptual modeling approaches can be used to support enterprise stakeholders to represent and thereby understand the changes.

This paper proposes a conceptual model that can be used by enterprise stakeholders to describe and represent concepts related to enterprise change, so that they can better understand and respond to changes.

Our future work will focus on addressing the key limitations identified in Section 8. One of such limitation is in the validation and evaluation methods. We intend to address this using empirical validation method i.e., deploying this language to enterprise managers to use as a change modeling mechanism. This would help us to collect data for a more rigorous evaluation, and also collect feedback for future improvement. Additionally, we will work towards developing tool to support stakeholders in modeling enterprise changes and performing some useful analysis that can help to detect changes and respond to them effectively, thereby facilitating enterprise agility.

\section{References}

[1] S. Dongback and A. LaPaz, "Exploring the Dark Side of IS in Achieving Organizational Aagility.," Communications of the ACM, vol. 51, no. 11, pp. 136-139, 2008.

[2] T. The Open Group, The Open Group Standard, TOGAF Version 9.1: Evaluation Copy. Van Haren Publishing, 2011.

[3] P. P. Tallon and A. Pinsonneault, "Competing perspectives on the link between strategic information technology alignment and organizational agility: Insights from a mediation model.," MIS Quarterly, vol. 35, no. 2, pp. 463 - 486, 2011.

[4] Y.-H. Tseng and C.-T. Lin, "Enhancing enterprise agility by deploying agile drivers, capabilities and providers," Information Sciences, vol. 181, no. 17, pp. $3693-3708$, 2011 .

[5] M. van Oosterhout, E. Waarts, and J. van Hillegersberg, "Change factors requiring agility and implications for IT.," European Journal of Information Systems, vol. 15, no. 2, pp. 132-145, 2006

[6] J. Mylopoulos, "Conceptual modelling and telos 1," Conceptual modeling, databases, and CASE, pp. 363-376, 2008.

[7] J. Zachman, "The zachman framework for enterprise architecture," Zachman International, vol. 1b, pp. 1-15, 2002.
[8] M. M. Lankhorst, H. A. Proper, and H. Jonkers, "The architecture of the archimate language," in Enterprise, Business-Process and Information Systems Modeling, pp. 367-380, Springer, 2009.

[9] W. Engelsman, D. Quartel, H. Jonkers, and M. van Sinderen, "Extending enterprise architecture modelling with business goals and requirements.," Enterprise Information Systems, vol. 5, no. 1, pp. 9 - 36, 2011.

[10] E. S. Yu, "Social modeling and $\mathrm{i}^{*}$," in Conceptual Modeling: Foundations and Applications, pp. 99-121, Springer, 2009.

[11] G. Engels, R. Heckel, and S. Sauer, "Uml a universal modeling language?," in Application and Theory of Petri Nets 2000 (M. Nielsen and D. Simpson, eds.), vol. 1825 of Lecture Notes in Computer Science, pp. 24-38, Springer Berlin Heidelberg, 2000.

[12] T. Bmm Version 1.2, "Business motivation model (bmm) version 1.2 beta 2 specification," tech. rep., Technical Report dtc/2013-08-24, Object Management Group, Needham, Massachusetts, 2013.

[13] C. H. S. John, A. R. Cannon, and R. W. Pouder, "Change drivers in the new millennium: implications for manufacturing strategy research," Journal of Operations Management, vol. 19, no. 2, pp. 143 - 160, 2001.

[14] H. Jonkers, E. Proper, and M. Turner, "Togaf and archimate ${ }^{\circ}$ : A future together," A White Paper Published by The Open Group, vol. 192, pp. 1-15, 2009.

[15] H. Jonkers, H. van den Berg, M.-E. Iacob, and D. Quartel, "Archimate ${ }^{\circledR}$ extension for modeling the togaf implementation and migration phases," Reading, Berkshire: Whitepaper, The Open Group, vol. 1, pp. 1-18, 2010.

[16] R. Vecchiato and C. Roveda, "Strategic foresight in corporate organizations: Handling the effect and response uncertainty of technology and social drivers of change," Technological Forecasting and Social Change, vol. 77, no. 9, pp. 1527 - 1539, 2010. Strategic Foresight.

[17] M. Wolf, J. Vykoukal, and R. Beck, "Services Grid Competence as Driver of Business Agility in Turbulent Environments A Conceptual Model in the Financial Services Industry," in 43RD HAWAII INTERNATIONAL CONFERENCE ON SYSTEMS SCIENCES VOLS 1-5 (HICSS 2010), pp. 3731-3740, IEEE COMPUTER SOC, 2010.

[18] R. Fekri, A. Aliahmadi, and M. Fathian, "Predicting a model for agile npd process with fuzzy cognitive map: the case of iranian manufacturing enterprises," The International Journal of Advanced Manufacturing Technology, vol. 41, no. 11-12, pp. 1240-1260, 2009.

[19] D. Vazquez-Bustelo, L. Avella, and E. Fernández, "Agility drivers, enablers and outcomes: empirical test of an integrated agile manufacturing model," International Journal of Operations \& Production Management, vol. 27, no. 12, pp. 1303-1332, 2007.

[20] R. Wendler, "Development of the organizational agility maturity model," in Computer Science and Information Systems (FedCSIS), 2014 Federated Conference on, pp. 1197-1206, Sept 2014.

[21] L. B. Chonko and E. Jones, "The need for speed: Agility selling.," Journal of Personal Selling and Sales Management, vol. 25, no. 4, pp. 371 - 382, 2005.

[22] N. Horney, M. Eckenrod, G. McKinney, and R. Prescott, "From change projects to change agility.," People \& Strategy, vol. 37, no. 1, pp. $40-45,2014$. 
[23] E. Overby, A. Bharadwaj, and V. Sambamurthy, "Enterprise agility and the enabling role of information technology.," European Journal of Information Systems, vol. 15, no. 2, pp. 120 - 131, 2006.

[24] S. Izza, R. Imache, L. Vincent, and Y. Lounis, "An approach for the evaluation of the agility in the context of enterprise interoperability," in Enterprise Interoperability III (K. Mertins, R. Ruggaber, K. Popplewell, and X. Xu, eds.), pp. 3-14, Springer London, 2008.

[25] R. Dove, "Agile enterprise cornerstones: Knowledge, values, and response ability," in Business Agility and Information Technology Diffusion (R. Baskerville, L. Mathiassen, J. Pries-Heje, and J. DeGross, eds.), vol. 180 of IFIP International Federation for Information Processing, pp. 313-330, Springer US, 2005.

[26] D. J. Teece, "Explicating dynamic capabilities: the nature and microfoundations of (sustainable) enterprise performance," Strategic management journal, vol. 28, no. 13, pp. 1319-1350, 2007.

[27] W. B. Rouse, "A theory of enterprise transformation," Systems Engineering, vol. 8, no. 4, pp. 279-295, 2005.

[28] J. C. Nwokeji, T. Clark, B. Barn, and V. Kulkarni, "A conceptual framework for enterprise agility," in Proceedings of the 30th Annual ACM Symposium on Applied Computing, SAC '15, (New York, NY, USA), pp. 1242-1244, ACM, 2015.

[29] J. C. Nwokeji, "A framework for enterprise agility," in Proceedings of the 30th Annual ACM Symposium on Applied Computing, SAC '15, (New York, NY, USA), pp. 1249-1250, ACM, 2015.

[30] J. C. Nwokeji, T. Clark, B. Barn, V. Kulkarni, and S. O. Anum, "A data-centric approach to change management," in Enterprise Distributed Object Computing Conference (EDOC), 2015 IEEE 19th International, pp. 185-190, Sept 2015.

[31] A. Josey, M. Lankhorst, I. Band, H. Jonkers, and D. Quartel, An Introduction to the Archimate 3.0 Specification. Archimate, archimate 3.0 ed., 2016.

[32] J. Nwokeji, T. Clark, B. Barn, and V. Kulkarni, "Automated Completeness Check in KAOS," in Advances in Conceptual Modeling (M. Indulska and S. Purao, eds.), vol. 8823 of Lecture Notes in Computer Science, pp. 133-138, Springer International Publishing, 2014.

[33] A. R. Hevner, S. T. March, J. Park, and S. Ram, "Design science in information systems research.," MIS Quarterly, vol. 28, no. 1, pp. 75 - 105, 2004.

[34] A. R. Hevner, "A three cycle view of design science research," Scandinavian journal of information systems, vol. 19, no. 2, p. 4, 2007.

[35] D. Babik, L. Iyer, and E. Ford, "Towards a comprehensive online peer assessment system," in Design Science Research in Information Systems. Advances in Theory and Practice (K. Peffers, M. Rothenberger, and B. Kuechler, eds.), vol. 7286 of Lecture Notes in Computer Science, pp. 1-8, Springer Berlin Heidelberg, 2012.

[36] A. Hjalmarsson and D. Rudmark, "Designing digital innovation contests," in Design Science Research in Information Systems. Advances in Theory and Practice (K. Peffers, M. Rothenberger, and B. Kuechler, eds.), vol. 7286 of Lecture Notes in Computer Science, pp. 9-27, Springer Berlin Heidelberg, 2012.
[37] B. Kitchenham, "Procedures for performing systematic reviews," Keele, UK, Keele University, vol. 33, no. 2004, pp. 1-26, 2004.

[38] T. Clark, P. Sammut, and J. Willans, "Applied metamodelling: a foundation for language driven development," arXiv preprint arXiv:1505.00149, vol. 1, pp. 1-244, 2015.

[39] Y. Wand and R. Weber, "Research commentary: information systems and conceptual modelinga research agenda," Information systems research, vol. 13, no. 4, pp. 363-376, 2002.

[40] J. Nwokeji, T. Clark, and B. Barn, "Towards a comprehensive meta-model for kaos," in Model-Driven Requirements Engineering (MoDRE), 2013 International Workshop on, pp. 30-39, 2013.

[41] A. Van Lamsweerde, "Goal-oriented requirements enginering: a roundtrip from research to practice [enginering read engineering]," in Requirements Engineering Conference, 2004. Proceedings. 12th IEEE International, pp. 4-7, Sept 2004.

[42] J. C. Nwokeji, T. Clark, and B. S. Barn, "A proposal for consolidated intentional modeling language," in Proceedings of the Second Workshop on Graphical Modeling Language Development, GMLD '13, (New York, NY, USA), pp. 12-22, ACM, 2013.

[43] M. Boukhebouze, Y. Amghar, A.-N. Benharkat, and Z. Maamar, "Towards an approach for estimating impact of changes on business processes," in Commerce and Enterprise Computing, 2009. CEC' 09 . IEEE Conference on, pp. 415-422, July 2009.

[44] W. J. Kettinger and V. Grover, "Special section: Toward a theory of business process change management.," Journal of Management Information Systems, vol. 12, no. 1 , pp. 9 - 30, 1995 .

[45] D. Steinberg, F. Budinsky, E. Merks, and M. Paternostro, EMF: eclipse modeling framework. Pearson Education, 2008.

[46] D. L. Moody, "Theoretical and practical issues in evaluating the quality of conceptual models: current state and future directions," Data \& Knowledge Engineering, vol. 55, no. 3, pp. 243-276, 2005.

[47] P. Hodkinson and H. Hodkinson, "The strengths and limitations of case study research," in Learning and Skills Development Agency Conference at Cambridge, vol. 1, pp. 5-7, 2001. 